\title{
Isothermal Crystallization of Poly(ethylene-co-glycidyl methacrylate)/Silica Nanocomposites
}

\author{
Jiann-Wen HuAng, ${ }^{1, \dagger}$ Chiun-Chia Kang, ${ }^{2}$ and Tse-Hsin CHEN $^{3}$ \\ ${ }^{1}$ Department of Styling \& Cosmetology, Tainan Woman's College of Arts \& Technology, \\ 529 Chung Cheng Rd., Yung Kang City, 710, Taiwan, R.O.C. \\ ${ }^{2} R \& D$ Center, Taroko International Co., Ltd., 473 Jong Shan South. Rd., Yung Kang City 710, Taiwan \\ ${ }^{3}$ Department of Chemistry, National Cheng Kung University, No. 1, Ta-Hsueh Road, Tainan 701, Taiwan
}

(Received December 15, 2004; Accepted April 23, 2005; Published August 15, 2005)

\begin{abstract}
Aminopropyltriethoxysilane was used to modify nano-size silica particles (A-Silica), and silanation was studied by ${ }^{29} \mathrm{Si}$ and ${ }^{13} \mathrm{C}$ CP MAS NMR. $3 \mathrm{wt} \%$ original silica (Silica) and modified silica (A-Silica) particles were blended with poly(ethylene-co-glycidyl mathacrylate) (PEGMA) in a twin screw extruder. The dispersibility of these nanocomposites was examined by transmission electron microscopy. The equilibrium melting temperature was estimated by linear and nonlinear Hoffman-Weeks relations, and the kinetics of isothermal crystallization were described by Avrami, Tobin, Malkin, and Urbanovici-Segal models. The results showed that PEGMA containing the modified nano-silica gave the highest equilibrium melting temperature and slowest isothermal crystallization rate. The above four kinetic models predicted the same ranking order in crystallization rate: PEGMA > PEGMA/Silica > PEGMA/A-Silica. [DOI 10.1295/polymj.37.550]

KEY WORDS Nanocomposite / Silanation / Silica / Equilibrium Melting Temperature / Isothermal Crystallization /
\end{abstract}

Inorganic particles are widely used as reinforcing agents in organic composites. The nanocomposites with nanoscale particles dispersed in the resin matrix exhibit markedly improved properties, such as strength, modulus and heat resistance, etc. ${ }^{1-5}$ Nanoparticles also serve as a nucleating agent to enhance crystallization and increase crystallinity. ${ }^{6-8}$ The incorporation of nanometer particles into a polymer matrix introduces an enormous number of interfacial surface areas in the system and thus alters the crystallization kinetics of the polymer.

The diameter of a nanoparticle is very small and the van der Waals radius of particles is always larger than the distance between centers of mass, leading to a stronger tendency of agglomeration of particles, and inferior distribution of nanoparticles. The dispersion of nanoparticles is the most important subject in studying how to apply the nanoparticles technology successfully to polymer materials. ${ }^{9-11}$ Silylation is most commonly used for surface modification to avoid agglomeration and phase separation owing to improvement the compatibility and adhesion between the inorganic particles and the organic matrix. ${ }^{12-16}$

In the present study, 3 wt $\%$ nano-silica unmodified or modified by $\gamma$-aminopropyltriethoxysilane, was blended with epoxy-modified polyethylene (poly(ethylene-co-glycidyl methacrylate); PEGMA), and the dispersion was investigated. Avrami, Tobin, Malkin and Urbanovici-Segal crystallization kinetic models were used to simulate the effects of nanoparticles on the isothermal crystallization kinetics of PEGMA.

\section{EXPERIMENTAL}

\section{Materials}

Commercial grade PEGMA (trade name: CG5004) was supplied by Sumitomo Chemical Co. Ltd., containing $81 \mathrm{wt} \%$ ethylene and $19 \mathrm{wt} \%$ glycidyl methacrylate. Nano-silica (trade name: A-200) and $\gamma$ aminopropyltriethoxysilane (APTS) were purchased from Degussa. Tetrahydrofuran (THF) and triethyleneamine (TEA) were supplied from Aldrich. All materials were used as received without purification.

\section{Surface Modification of Nano-Silica}

The silanation of nano-sized silica was carried out as follows: To $10 \mathrm{~g}$ nano-sized silica and $0.5 \mathrm{~g}$ TEA diluted in $2 \mathrm{~g}$ water were stierred in $100 \mathrm{~g}$ THF for $1 \mathrm{~h}$ and then $1 \mathrm{~g}$ APTS was added. ${ }^{17-19}$ The mixture was sonicated for $2 \mathrm{~h}$. The modified silica (A-Silica) was separated using a centrifuge and dried at $50^{\circ} \mathrm{C}$ under vaccum for $6 \mathrm{~h}$.

\section{Preparation of PEGMA/Nano-Silica Composites}

PEGMA was compounded respectively with $3 \mathrm{wt} \%$ unmodified silica (Silica) or modified silica (A-Silica) in a twin-screw extruder (Continent Machinery Company, Model CM-MTE) at $150^{\circ} \mathrm{C}$ and $300 \mathrm{rpm}$ to pre-

†To whom correspondence should be addressed (FAX: +886-6-2433812, E-mail: jw.huang@msa.hinet.net). 
pare nanocomposites PEGMA/Silica and PEGMA/ A-Silica. All materials were dried in a vacuum oven at room temperature for $6 \mathrm{~h}$ before compounding.

\section{CHARACTERIZATIONS}

\section{Isothermal Crystallization}

The crystallization behavior of PEGMA, and PEGMA/Silica and PEGMA/A-Silica nanocomposites was investigated with a differential scanning calorimeter (Perkin-Elmer DSC-1). The calorimeter was calibrated using indium standards. All operations were carried out in a nitrogen atmosphere. Before data gathering, the samples were heated to $120^{\circ} \mathrm{C}$ and held in the molten state for $5 \mathrm{~min}$ to eliminate the influence of thermal history. The sample melts were subsequently quenched at a rate of $100^{\circ} \mathrm{C} / \mathrm{min}$ to reach the specific temperatures and kept at the respective temperatures for $1 \mathrm{~h}$. After isothermal crystallization was completed, the samples were heated again to $120^{\circ} \mathrm{C}$ at a rate of $10^{\circ} \mathrm{C} / \mathrm{min}$ to measure the melting temperatures.

\section{NMR Measurements}

Solid-state ${ }^{13} \mathrm{C}$ and ${ }^{29} \mathrm{Si}$ MAS NMR measurements were carried out using a BRUKER AVANCE 400. Magic angle spinning (MAS) was performed at $5 \mathrm{kHz}$ spinning rate in the ${ }^{13} \mathrm{C}$ (at $100.57 \mathrm{MHz}$ ) and ${ }^{29} \mathrm{Si}$ (at $79.46 \mathrm{MHz}$ ). The contact time in the ${ }^{29} \mathrm{Si} \mathrm{CP}$ (cross polarization) MAS NMR studies was $5 \mathrm{~ms}$. All solid experiments were done at ambient temperature. Solution ${ }^{13} \mathrm{C}$ (at $100.6 \mathrm{MHz}$ ) NMR spectra were measured in $\mathrm{CDCl}_{3}$ on a Bruker Avance DRX 300 spectrometer.

\section{Transmission Electron Microscopy}

TEM photographs of ultrathin sections of the nanocomposites were taken on a Jeol JEM-1200 CXII transmission electron microscope at an acceleration voltage of $120 \mathrm{kV}$.

\section{RESULTS AND DISCUSSION}

\section{Silanation of Silica}

${ }^{29} \mathrm{Si}$ CP MAS NMR was proven to be a method for characterization of silicate materials. ${ }^{17}$ The NMR spectra of unmodified silica and modified one (ASilica) are shown in Figures 1a and 1b, respectively. The signals at $-104.6,-108.3$, and $-111.2 \mathrm{ppm}$ are usually assigned, respectively, to geminal silanols, free silanols, and siloxane groups. The peak of geminal silanols of modified silica was reduced, suggesting that $\mathrm{OH}$ groups on silica surface reacted with APTS. For the modified silica nanoparticles, two additional peaks are found at -57.6 and $-68.6 \mathrm{ppm}^{18,19}$

Figure 1c shows a ${ }^{13} \mathrm{C}$ NMR spectrum of neat APTS (dissolved in $\mathrm{CDCl}_{3}$ ) and Figure 1d shows a ${ }^{13} \mathrm{C}$ CP MAS NMR spectrum of A-Silica. In Figure $1 \mathrm{~d}$, three peaks were observed around 9.8, 24.5 and $45.9 \mathrm{ppm}$, which could be assigned to $\mathrm{C}^{\prime}, \mathrm{C} 2^{\prime}$ and $\mathrm{C}^{\prime}$. In the spectrum of A-Silica, two peaks (C4 and C5) disappeared, as seen by comparison with the spectrum of neat APTS in Figure 1c, which implies that alkoxy groups reacte with silanol groups on the silica particle surface.

\section{Dispersion of Nano-Silica in PEGMA}

It is generally difficult for inorganic nanoparticles to be dispersed in organic polymer matrixes because of particle aggregation and incompatibility between the particles and polymer. As shown by a TEM micrograph in Figure 2a, there were some aggregates of silica particles in the PEGMA/Silica blend, although PEGMA containing epoxy groups improve the compatibility of PEGMA and silica particles. However, silica particles modified by APTS were well dispersed in the PEGMA/A-Silica blend (Figure 2b). It is believed that there are strong interactions or some reactions between the modified silica particles and PEGMA. Many studies demonstrate that amine groups are capable of reacting with epoxy groups, as shown in the following scheme: ${ }^{20-24}$

\section{Equilibrium Melting Temperature}

The equilibrium melting temperature $\left(T_{\mathrm{m}}^{0}\right)$ of a polymer is an important thermodynamic parameter of crystallizable chain polymers, as it is the reference temperature from which the driving force for crystallization is defined. ${ }^{25-28} T_{\mathrm{m}}^{0}$ is the melting point of a perfect and infinitely large crystal.

Several methods are used to estimate such an equilibrium melting temperature. ${ }^{25-30} \mathrm{In}$ this article, $T_{\mathrm{m}}^{0}$ was evaluated from DSC measurements of melting temperature $\left(T_{\mathrm{m}}\right)$ conducted after isothermal crystallization at $T_{\mathrm{c}}$ was completed. Hoffman-Weeks rela$\operatorname{tion}^{30}$ is widely used to estimate the equilibrium melting temperature, determined by extrapolation of $T_{\mathrm{m}}$ vs. $T_{\mathrm{c}}$ to $T_{\mathrm{m}}=T_{\mathrm{c}}$ (called linear $\left.\mathrm{H}-\mathrm{W}\right)$ :

$$
T_{\mathrm{m}}^{\prime}=T_{\mathrm{m}}^{\text {OLHW }}\left(1-\frac{1}{\gamma^{\mathrm{LHW}}}\right)+\frac{T_{\mathrm{c}}}{\gamma^{\mathrm{LHW}}}
$$

with $\gamma^{\mathrm{LHW}}=l / l^{*}$, where $l$ and $l^{*}$ are the lamellar thickness at the time of melting and the thickness of

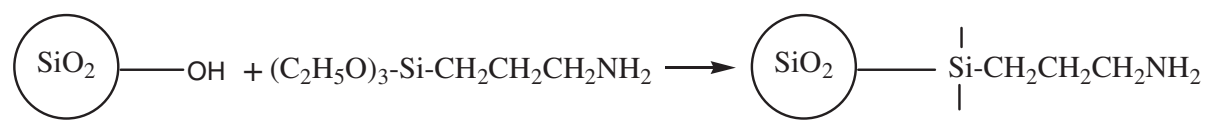




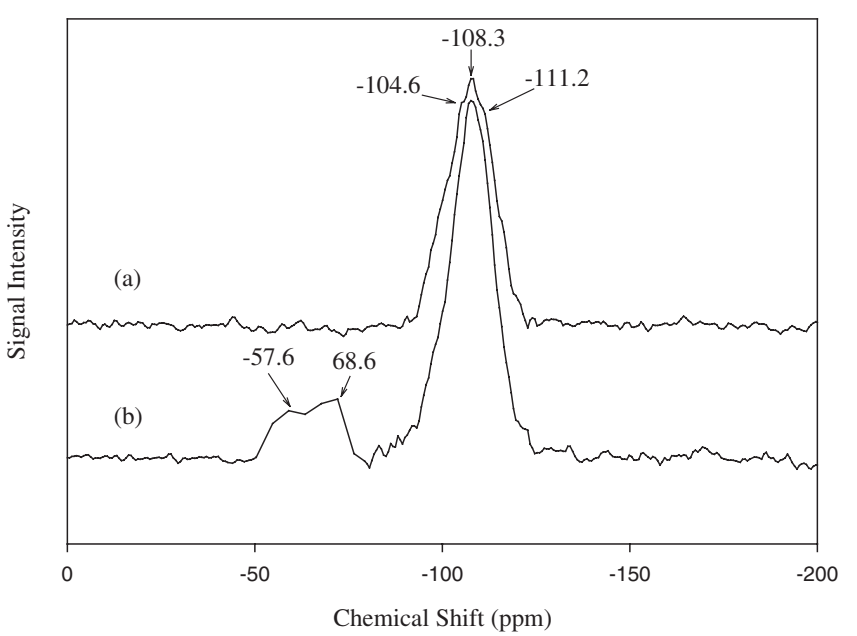

(a)(b)

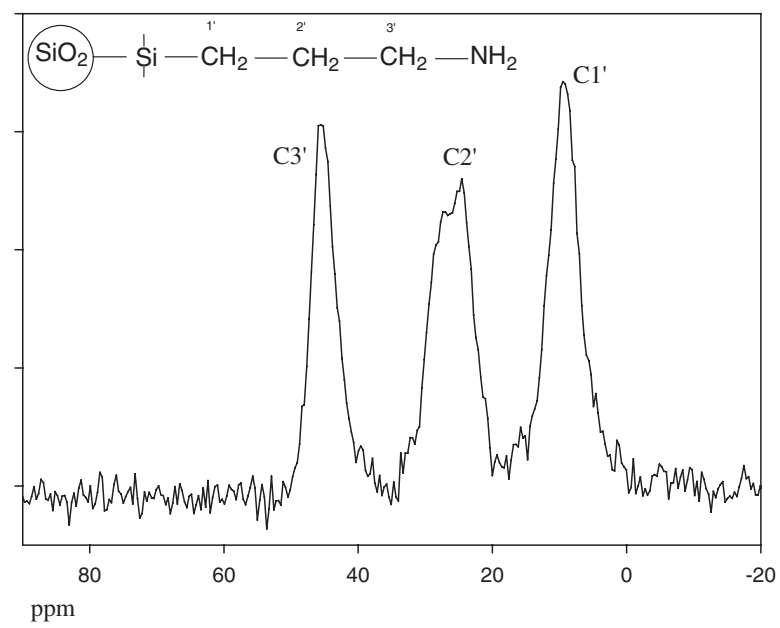

(d)

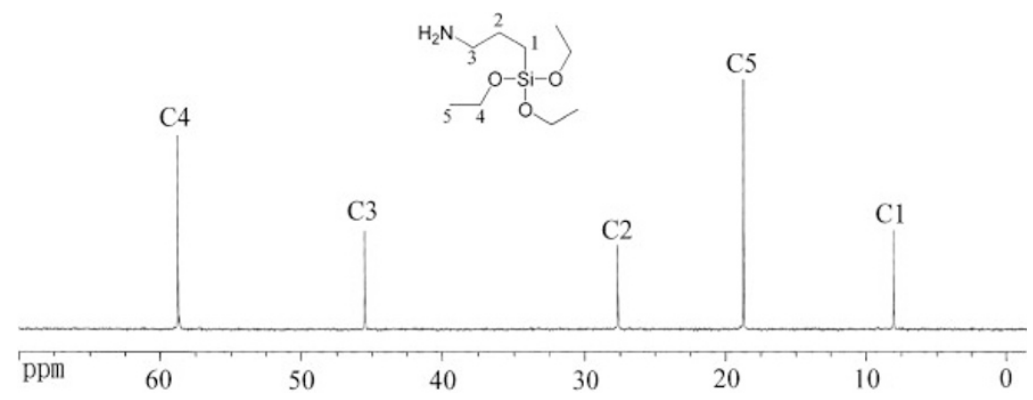

(c)

Figure 1. ${ }^{29} \mathrm{Si}$ CP MAS NMR spectra of (a) unmodified silica and (b) modified silica (A-Silica); (c) ${ }^{13} \mathrm{C}$ NMR spectra of neat APTS (dissolved in $\mathrm{CDCl}_{3}$ ); and (d) ${ }^{13} \mathrm{C}$ CP MAS NMR spectra of A-Silica.
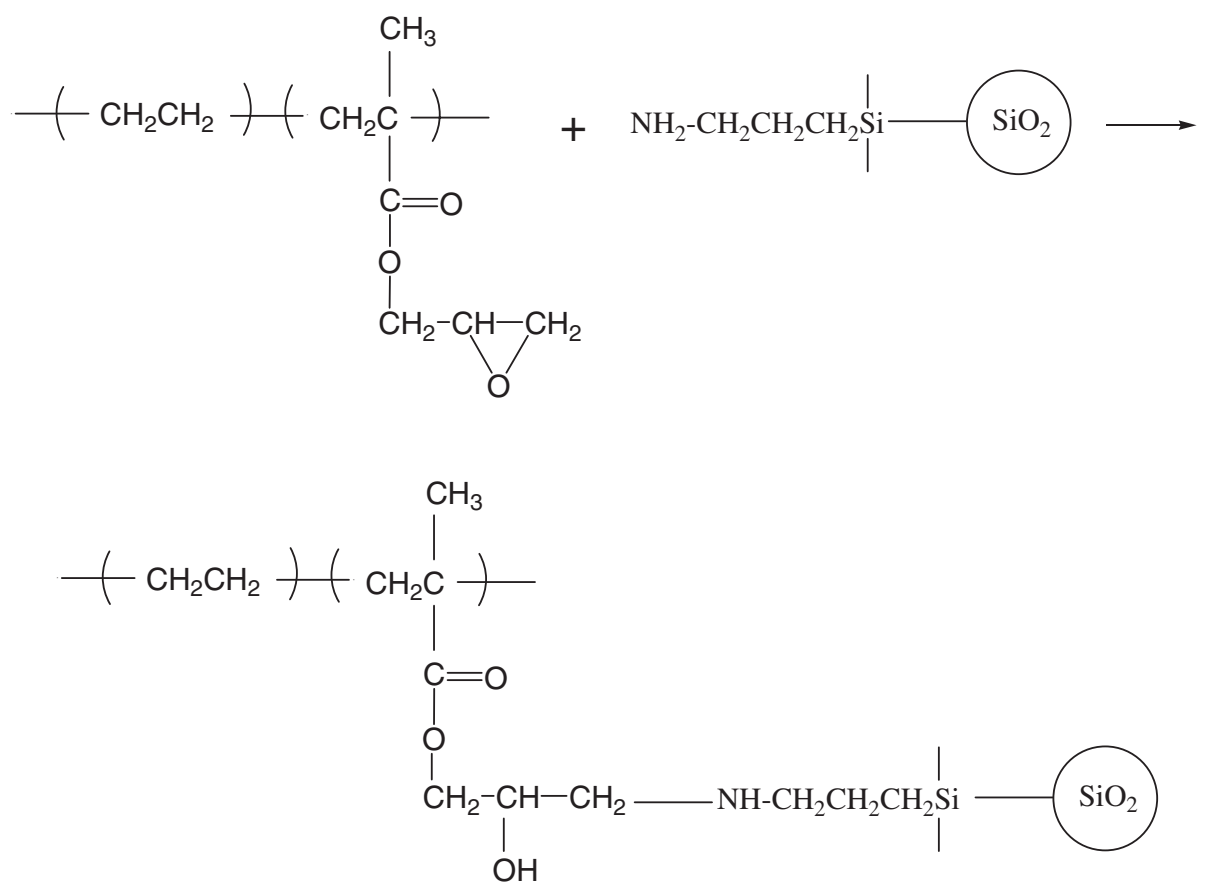

the critical nucleus at $T_{\mathrm{c}}$, respectively. ${ }^{31} T_{\mathrm{m}}^{\prime}$ is the observed melting temperature and $T_{\mathrm{c}}$ is the crystallization temperature. Figures $3 \mathrm{a}, 3 \mathrm{~b}$ and $3 \mathrm{c}$ show plots of $T_{\mathrm{m}} v s . T_{\mathrm{c}}$ for PEGMA, PEGMA/Silica and PEGMA/A-Silica, respectively, and the equilibrium melting temperature $\left(T_{\mathrm{m}}^{\mathrm{OLHW}}\right)$ calculated from the 


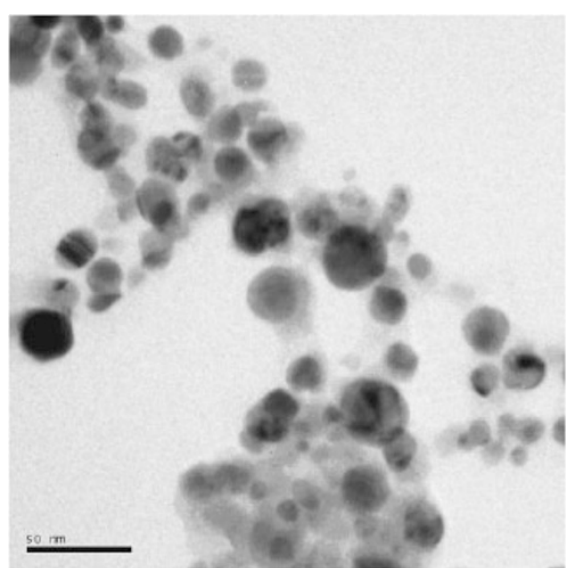

(a)

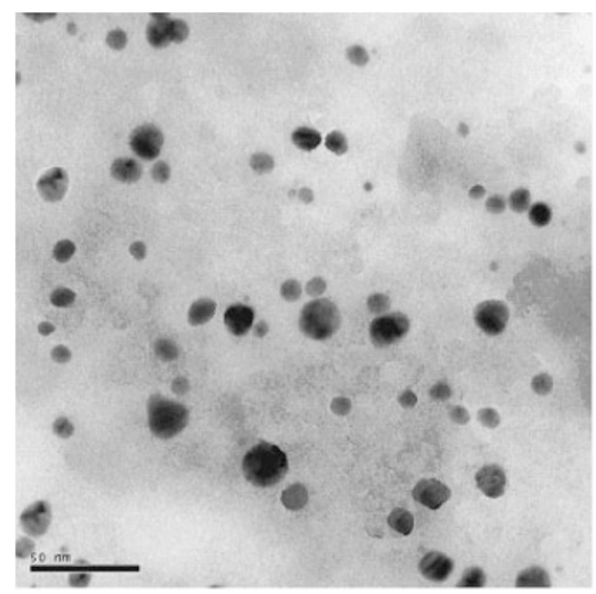

(b)

Figure 2. TEM micrographs of PEGMA/silica nanocomposites: (a) PEGMA/Silica; (b) PEGMA/A-Silica.

Table I. Equilibrium Melting Temperature of PEGMA, PEGME/Silica and PEGME/A-Silica

\begin{tabular}{lcccc}
\hline \multicolumn{1}{c}{ Sample } & $\begin{array}{c}T_{\mathrm{m}}^{\text {0LHW }} \\
(\mathrm{K})\end{array}$ & $\gamma^{\mathrm{LHW}}$ & $\begin{array}{c}T_{\mathrm{m}}^{\text {ONLHW }} \\
(\mathrm{K})\end{array}$ & $\gamma^{\text {NLHW }}$ \\
\hline PEGMA & 402 & 1.24 & 443 & 1.00 \\
\hline PEGME/Silica & 406 & 1.18 & 452 & 1.00 \\
\hline PEGME/A-Silica & 418 & 1.15 & 466 & 1.00 \\
\hline
\end{tabular}

linear $\mathrm{H}-\mathrm{W}$ are listed in Table I. Linear $\mathrm{H}-\mathrm{W}$ analysis gave $\gamma^{\mathrm{LHW}}$ of $1.24,1.18$ and 1.15 , respectively, for PEGMA, PEMGA/Silica and PEMGA/A-Silica; the values were virtually meaningless as these $\gamma^{\mathrm{LHW}}$ values imply rapid and significant thickening of polymer lamellae at very early stage of crystallization. ${ }^{32-34}$ The basic assumption of the linear $\mathrm{H}-\mathrm{W}$ is that the thickening coefficient $\gamma^{\mathrm{LHW}}$ for lamellae is independent of $T_{\mathrm{c}}$ and time, and there is a linear relation between observed $T_{\mathrm{m}}$ and $T_{\mathrm{c}}$. This assumption is shown to underestimate the equilibrium melting temperature and overestimate the thickening coefficient. ${ }^{32-34}$

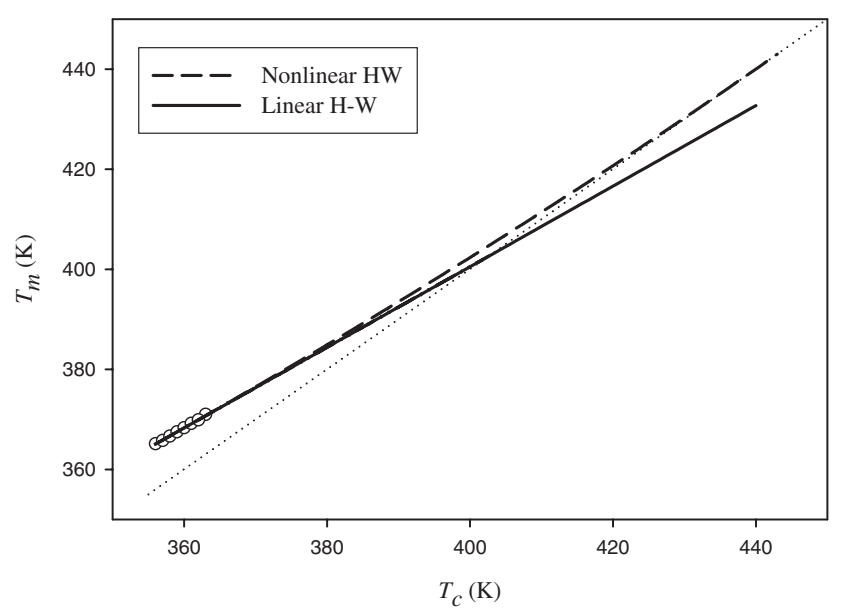

(a)

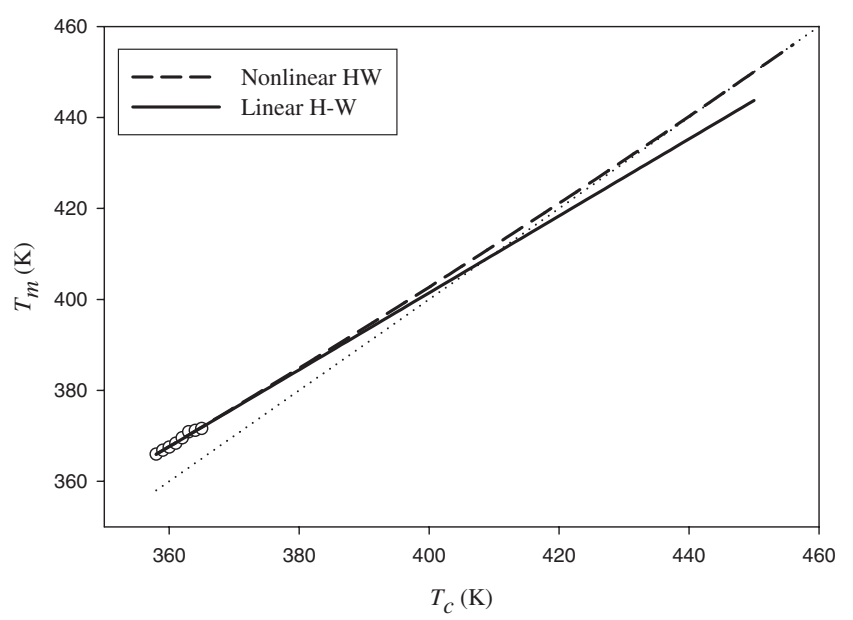

(b)

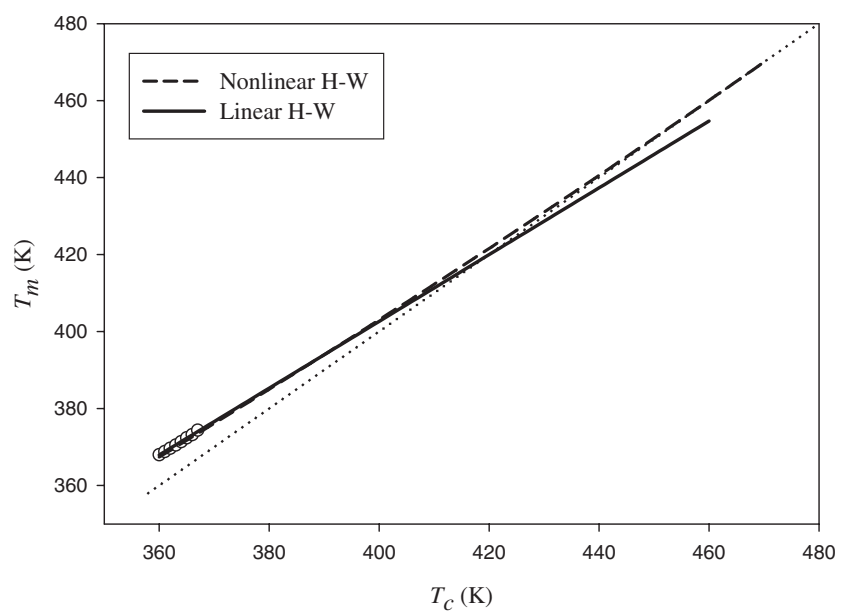

(c)

Figure 3. Comparisons of linear $\mathrm{H}-\mathrm{W}$ and nonlinear $\mathrm{H}-\mathrm{W}$ plots for (a) PEGMA, (b) PEGMA/Silica, and (c) PEGMA/ A-Silica.

Alamo et al. ${ }^{32}$ explain non-linearity in the observed $T_{\mathrm{m}}$ and $T_{\mathrm{c}} . l^{*}$ should be dependent on the degree of undercooling $\left(\Delta T=T_{\mathrm{m}}-T_{\mathrm{c}}\right)$ and $l^{*}=C_{1} / \Delta T+C_{2}$, where $C_{1}$ and $C_{2}$ are constant. But $C_{2}$ is always 
neglected in linear H-W. A Gibbs-Thomson equation $^{25-27}$ based on thermodynamics is an important theory to estimate the equilibrium melting temperature, but some limitations to the theory have been pointed out. ${ }^{27,33}$ Marand and coworkers ${ }^{33,34}$ derived, from Gibbs-Thomson equation, a nonlinear HoffmanWeeks equation (nonlinear $\mathrm{H}-\mathrm{W}$ ):

$$
\begin{aligned}
& M=\gamma\left(\frac{\sigma_{\mathrm{e}}^{l}}{\sigma_{\mathrm{em}}}\right)(X+a) \\
& M=\frac{T_{\mathrm{m}}^{\text {ONLHW }}}{T_{\mathrm{m}}^{\text {ONLHW }}-T_{\mathrm{m}}} \\
& X=\frac{T_{\mathrm{m}}^{\text {ONLW }}}{T_{\mathrm{m}}^{0 \mathrm{NLHW}}-T_{\mathrm{c}}} \\
& a=\frac{\Delta H_{\mathrm{f}} C_{2}}{2 \sigma_{\mathrm{e}}^{l}}
\end{aligned}
$$

where $T_{\mathrm{m}}^{0 \mathrm{NLHW}}$ and $\gamma^{\mathrm{NLHW}}$ are the equilibrium melting temperature and thickening coefficient in the nonlinear treatment, $\sigma_{\mathrm{e}}^{l}$ is the interfacial energy associated with the basal plane of the mature crystallite, $\sigma_{\mathrm{em}}$ is the fold surface free energy associated with a nucleus of critical size including the extra lateral surface energy due to fold protrusion and the mixing entropy associated with stems of different lengths, and $\Delta H_{\mathrm{f}}$ is the heat of fusion of crystal. $\sigma_{\mathrm{e}}^{l}$ is assumed equal to $\sigma_{\mathrm{em}}$ in most cases. ${ }^{32}$ According to eq 2, plots of M versus X should give a constant $\gamma^{\mathrm{NLHW}}$ for a specified $T_{\mathrm{m}}^{0 \mathrm{NLHW}}$. Figure 4 shows the variation of $\gamma^{\mathrm{NLHW}}$ with the value chosen for the equilibrium melting temperature. The "true" $T_{\mathrm{m}}^{\text {ONLHW }}$ obtained by this method is found when $\gamma^{\mathrm{NLHW}}=1$. The $T_{\mathrm{m}}^{\mathrm{NLHW}}$ of plain PEGMA, PEGMA/ Silica, and PEGMA/A-Silica are listed in Table I. The relations of $T_{\mathrm{m}}$ and $T_{\mathrm{c}}$ from the nonlinear $\mathrm{H}-\mathrm{W}$ are also shown in Figure 3 for comparison with the linear $\mathrm{H}-\mathrm{W}$. There was an apparent difference between

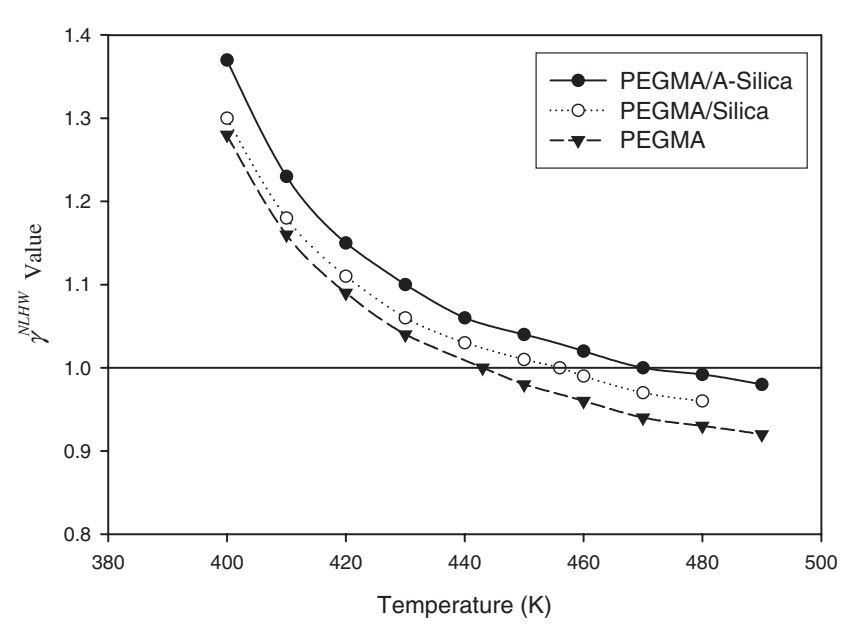

Figure 4. Thickening coefficients calculated at different specific equilibrium melting temperatures. the linear and nonlinear $\mathrm{H}-\mathrm{W}$, the latter nonlinear $\mathrm{H}-\mathrm{W}$ estimate giving a higher value in all samples.

The equilibrium melting temperature of a crystalline polymer is defined as the melting temperature of a perfect crystal formed by infinite molecular weight chains. Both $T_{\mathrm{m}}^{0 \mathrm{LHW}}$ and $T_{\mathrm{m}}^{0 \mathrm{NLHW}}$ of PEGMA nanocomposites with silica were higher than those of neat PEGMA; this means that the crystals in PEGMA/Silica nanocomposites are more perfect than those of plain PEGMA. $T_{\mathrm{m}}^{0 \mathrm{LHW}}$ or $T_{\mathrm{m}}^{\mathrm{ONLHW}}$ of PEGMA/A-Silica was even much higher. ${ }^{8}$

\section{Isothermal Crystallization Kinetics}

Figures 5a, 5b, and 5c show DSC exotherms evolved during isothermal crystallization of PEGMA, PEGMA/Silica, and PEGMA/A-Silica, respectively. The heat of crystallization at a constant temperature can be obtained by measuring the area of the thermogram peak. ${ }^{35}$ The relative crystallinity as a function of time, $X_{t}$, can be calculated as the ratio of exothermic peak area at time $t$ to infinite time:

$$
X_{t}=\frac{\int_{0}^{t}\left(\frac{d H_{\mathrm{c}}}{d t}\right) d t}{\int_{0}^{\infty}\left(\frac{d H_{\mathrm{c}}}{d t}\right) d t}
$$

where $d H_{\mathrm{c}}$ is the enthalpy of crystallization released during an infinitesimal time interval $d t$. Figures $6 \mathrm{a}$, $6 \mathrm{~b}$ and $6 \mathrm{c}$ show the relative crystallinity of PEMGA, PEGMA/Silica, and PEGMA/A-silica, respectively.

\section{Avrami Model}

The crystallization process is usually treated as a series of two stages: the primary crystallization stage and the secondary one. Avrami equations ${ }^{36-38}$ were used to analyze the overall isothermal crystallization process:

$$
X_{t}=1-\exp \left(-\left(K_{\mathrm{a}} t\right)^{n_{\mathrm{a}}}\right)
$$

where $X_{t}$ is the relative crystallinity, $t$ is crystallization time, $K_{\mathrm{a}}$ is the Avrami crystallization rate constant, and $n_{\mathrm{a}}$ is the Avrami exponent. The rate constant is usually written in composite form (eq 5), where $k_{\mathrm{a}}=$ $K_{\mathrm{a}}^{n_{\mathrm{a}}}$ is not only a function of temperature, but also a function of Avrami exponent.

$$
X_{t}=1-\exp \left(-k_{\mathrm{a}} t_{\mathrm{a}}^{*}\right)
$$

However, $K_{\mathrm{a}}$ is more preferable than $k_{\mathrm{a}}$ because it is independent of Avrami exponent and its dimension is given in (time $\left.{ }^{-1}\right){ }^{39-41} K_{\mathrm{a}}$ and $n_{\mathrm{a}}$ were calculated by fitting experimental data of $X_{t}$ to eq 4 and the result are shown in Table II.

The crystallization rate constant, $K_{\mathrm{a}}$, of PEGMA, and PEGMA/Silica and PEGMA/A-Silica nanocom- 


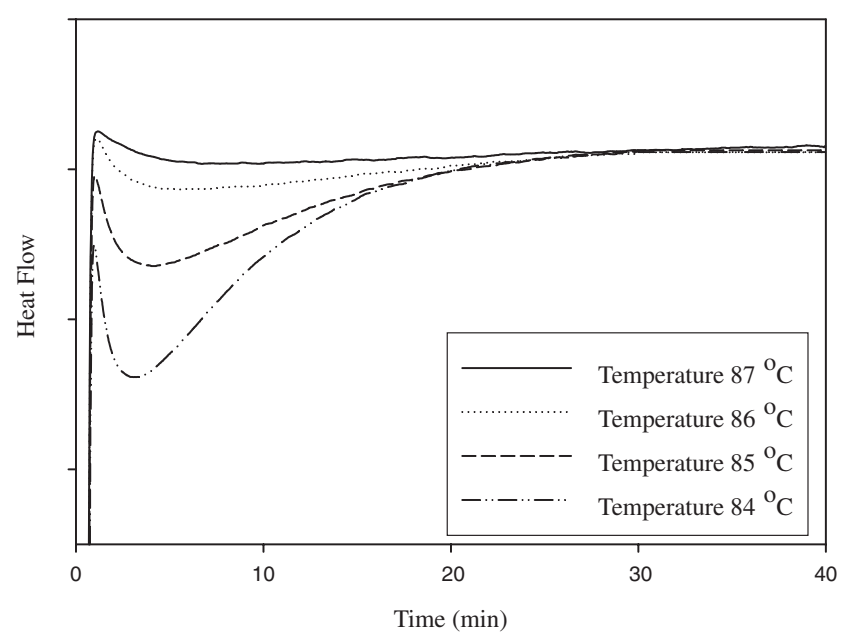

(a)

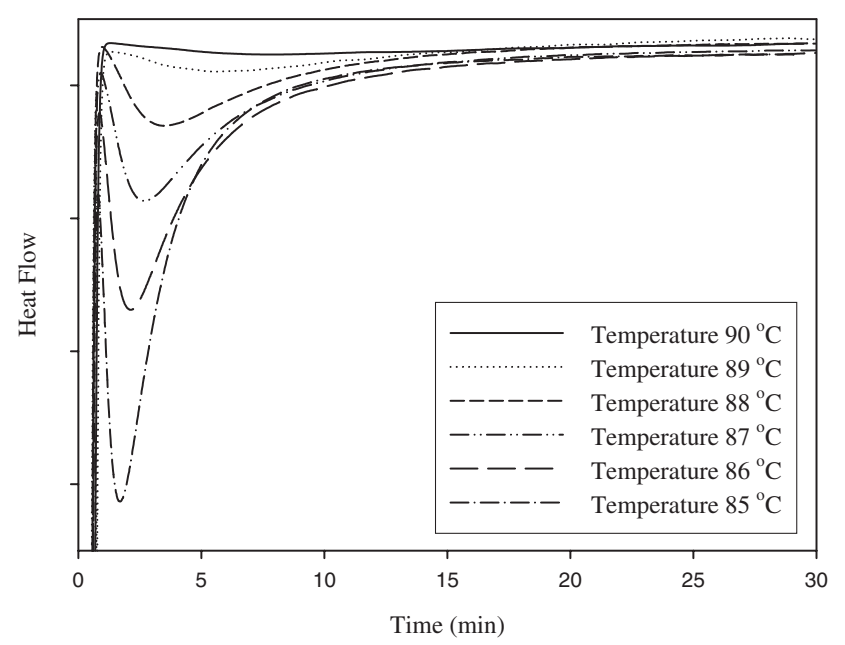

(b)

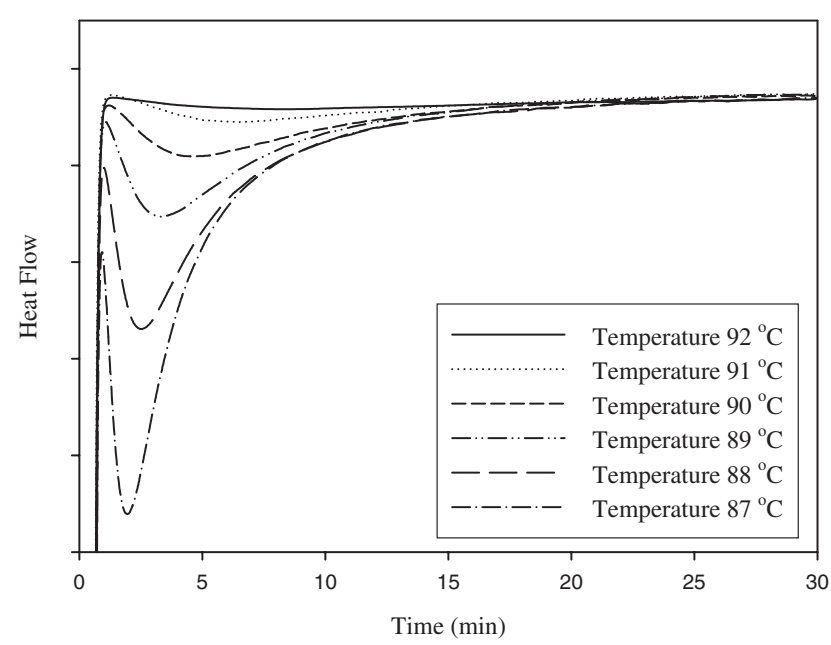

(c)

Figure 5. DSC isothermal measurement curves for (a) PEGMA, (b) PEGMA/Silica and (c) PEGMA/A-Silica.

posites decreased with crystallization temperature $\left(T_{\mathrm{c}}\right)$. The Avrami exponent $n_{\mathrm{a}}$ for neat PEGMA varied from 1.55 to 1.58 , suggesting crystallization to pro-

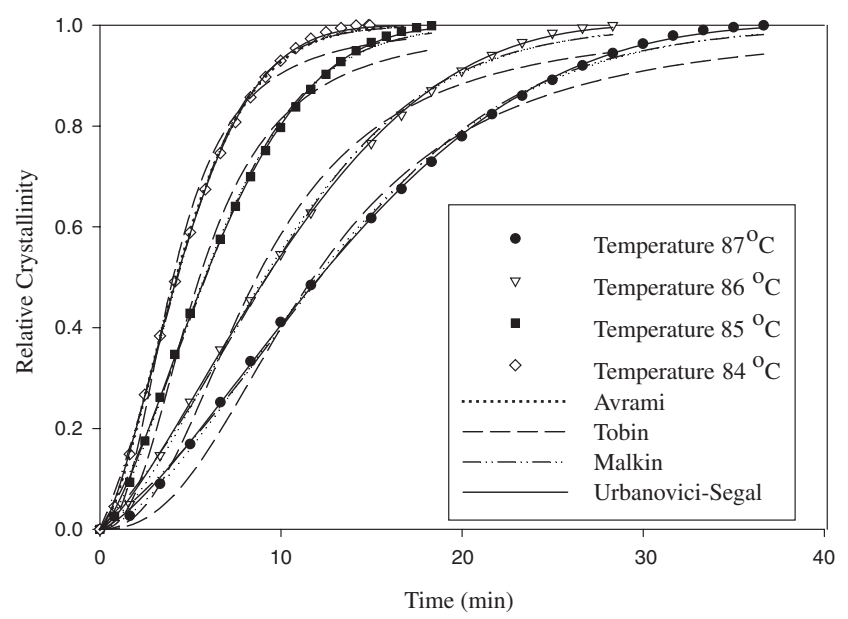

(a)

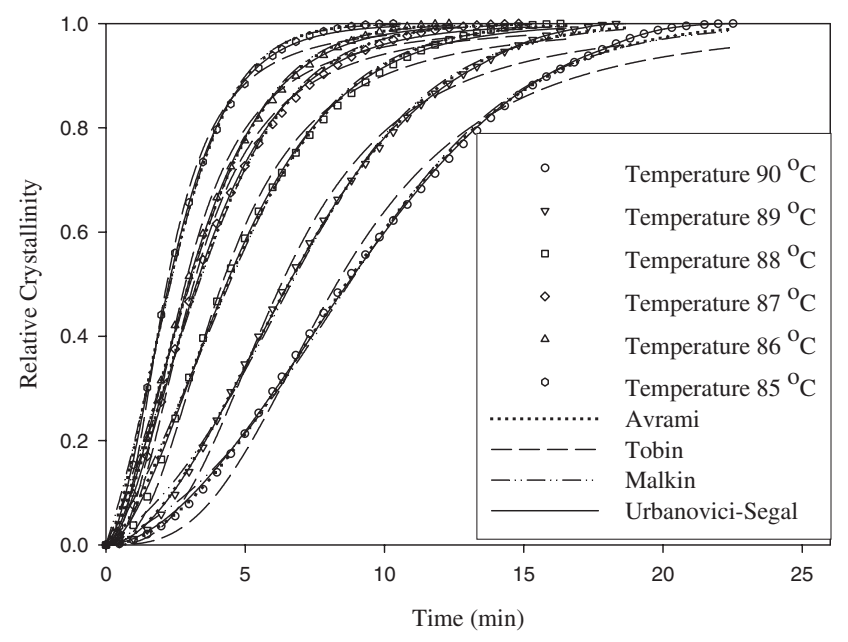

(b)

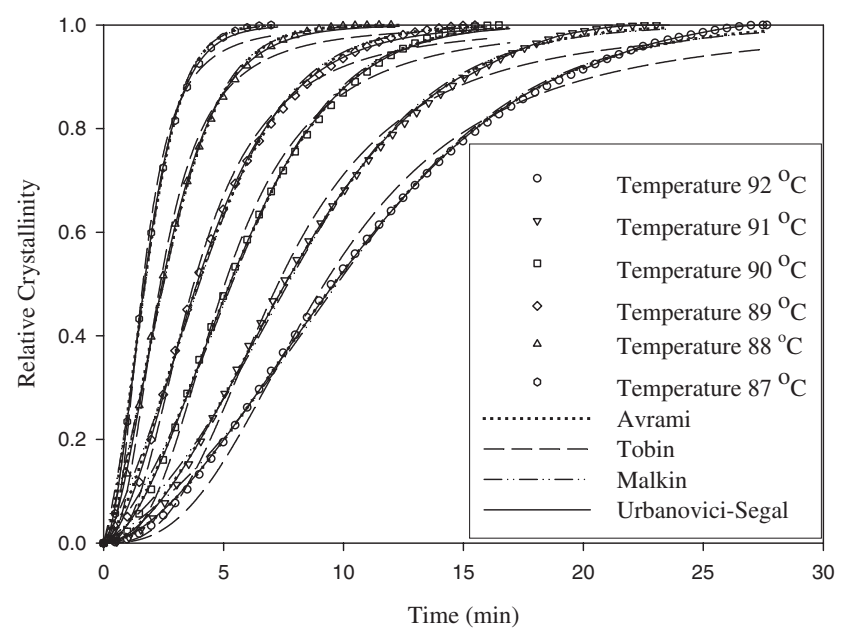

(c)

Figure 6. Relative crystallinity as a function of time at different crystallization temperatures, measured for (a) PEGMA, (b) PEGMA/Silica, and (c) PEGMA/A-Silica.

ceed by instantaneous nucleation and diffusioncontrolled growth. The addition of nano-silica gave $n_{\mathrm{a}}$ in a similar but somewhat wider range of 1.46 to 
Table II. Avrami kinetics parameters

\begin{tabular}{lcccc}
\hline \multirow{2}{*}{ Sample } & $\begin{array}{c}T_{\mathrm{c}} \\
\left({ }^{\circ} \mathrm{C}\right)\end{array}$ & $n_{\mathrm{a}}$ & $\begin{array}{c}K_{\mathrm{a}} \\
\left(\mathrm{min}^{-1}\right)\end{array}$ & $R^{2}$ \\
\hline PEGMA & 84 & 1.55 & 0.188 & 0.9996 \\
\cline { 2 - 5 } & 85 & 1.56 & 0.137 & 0.9993 \\
\cline { 2 - 5 } & 86 & 1.55 & 0.086 & 0.9986 \\
\cline { 2 - 5 } PEGMA/Silica & 87 & 1.58 & 0.062 & 0.9987 \\
\cline { 2 - 5 } & 85 & 1.50 & 0.343 & 0.9988 \\
\cline { 2 - 5 } & 86 & 1.49 & 0.262 & 0.9990 \\
\cline { 2 - 5 } & 87 & 1.46 & 0.236 & 0.9985 \\
\hline PEGMA/A-Silica & 88 & 1.56 & 0.181 & 0.9989 \\
\cline { 2 - 5 } & 89 & 1.85 & 0.125 & 0.9995 \\
\cline { 2 - 5 } & 87 & 1.75 & 0.096 & 0.9994 \\
\cline { 2 - 5 } & 88 & 1.52 & 0.465 & 0.9991 \\
\cline { 2 - 5 } & 89 & 1.53 & 0.200 & 0.9989 \\
\cline { 2 - 5 } & 90 & 1.73 & 0.153 & 0.9995 \\
\cline { 2 - 5 } & 91 & 1.78 & 0.107 & 0.9994 \\
\cline { 2 - 5 } & 92 & 1.75 & 0.084 & 0.9996 \\
\hline
\end{tabular}

1.85 for the two composite samples, which indicates that the addition of silica does not change the crystallization mechanism of PEGMA.

\section{Tobin Model}

The Avrami model is only appropriate for early stages of crystallization. Tobin developed a different expression by phase transformation kinetics taking account of a growth site impingement: ${ }^{42-44}$

$$
X_{t}=\frac{\left(K_{t} t\right)^{n_{t}}}{1+\left(K_{t} t\right)^{n_{t}}}
$$

where $K_{t}$ is the Tobin rate constant, and $n_{t}$ is the Tobin exponent. The exponent $n_{t}$ needs not be integer and is mainly governed by different types of nucleation and growth mechanism. The Tobin crystallization parameters, $K_{t}$ and $n_{t}$, can be found by fitting $X_{t}$ data obtained for each crystallization temperature to eq 6 and the result are shown in Table III.

Avrami exponent $n_{\mathrm{a}}$ was always lower than Tobin exponent $n_{t}$ at an arbitrary crystallization. Taking the average of the difference between the two values, $n_{t} \cong n_{\mathrm{a}}+1$, which is accordance with observation by other studies. ${ }^{45-47}$ The Tobin rate constant $K_{t}$ exhibited a similar trend to the Avrami rate constant $K_{\mathrm{a}}$.

Tobin model is usually written as,

$$
X_{t}=\frac{k_{t} t_{t}^{n_{t}^{*}}}{1+k_{t} t_{t}^{n_{t}^{*}}}
$$

where $k_{t}$ is the Tobin crystallization rate constant and $n_{t}^{*}$ is the Tobin exponent. $K_{t}$ is more preferable for the same reason as that stated above and its dimension is given in $\left(\right.$ time $\left.^{-1}\right) .{ }^{39-41}$
Table III. Tobin kinetics parameters

\begin{tabular}{lcccc}
\hline \multirow{2}{*}{ Sample } & $\begin{array}{c}T_{\mathrm{c}} \\
\left({ }^{\circ} \mathrm{C}\right)\end{array}$ & $n_{t}$ & $\begin{array}{c}K_{t} \\
\left(\mathrm{~min}^{-1}\right)\end{array}$ & $R^{2}$ \\
\hline PEGMA & 84 & 2.48 & 0.246 & 0.9898 \\
\cline { 2 - 5 } & 85 & 2.47 & 0.184 & 0.9884 \\
\cline { 2 - 5 } & 86 & 2.42 & 0.115 & 0.9855 \\
\cline { 2 - 5 } & 87 & 2.47 & 0.087 & 0.9863 \\
\hline PEGMA/Silica & 85 & 2.46 & 0.457 & 0.9955 \\
\cline { 2 - 5 } & 86 & 2.43 & 0.351 & 0.9937 \\
\cline { 2 - 5 } & 87 & 2.40 & 0.317 & 0.9955 \\
\cline { 2 - 5 } & 88 & 2.52 & 0.239 & 0.9947 \\
\cline { 2 - 5 } PEGMA/A-Silica & 89 & 2.60 & 0.158 & 0.9936 \\
\cline { 2 - 5 } & 90 & 2.62 & 0.120 & 0.9911 \\
\cline { 2 - 5 } & 87 & 2.64 & 0.608 & 0.9957 \\
\cline { 2 - 5 } & 88 & 2.50 & 0.422 & 0.9954 \\
\cline { 2 - 5 } & 89 & 2.49 & 0.266 & 0.9954 \\
\cline { 2 - 5 } & 90 & 2.75 & 0.197 & 0.9935 \\
\cline { 2 - 5 } & 91 & 2.82 & 0.137 & 0.9933 \\
\cline { 2 - 5 } & 92 & 2.74 & 0.108 & 0.9925 \\
\hline
\end{tabular}

\section{Malkin Model}

Malkin et al. ${ }^{48}$ derived the following equation for isothermal crystallization based on an assumption that the overall crystallization rate equals to the sum of two terms: the rate at which the degree of crystallinity varies as a result of the emergence of the primary nuclei, and the rate of variation in the degree of crystallinity due to crystal growth.

$$
X_{t}=1-\frac{C_{0}+1}{C_{0}+\exp \left(C_{1} t\right)}
$$

where $C_{0}$ is the Malkin exponent defined as the ratio of the crystal growth rate $G$ to the primary nucleation $I$ (i.e. $C_{0}=G / I$ ), and $C_{1}$ is the Malkin crystallization rate constant, related to the overall crystallization (i.e. $C_{1}=a G+b I$, where $a$ and $b$ are some specific constants). $C_{0}$ and $C_{1}$ were found by fitting with experimental data to eq 6 and the results are shown in Table IV. The parameter $C_{0}$ of PEGMA ranged from 4.23 to 4.65 for neat PEGMA, 3.22 to 7.86 for PEGMA/Silica, and 3.96 to 8.02 for PEGMA/ A-Silica. The most important feature of the Malkin model is not its physical meaning but the convenience of its analytical form. ${ }^{48}$ According to the Malkin's original article, ${ }^{48}$ this model seems to have better correlation with the experimental data than the Avrami model in some polymer systems. From regression coefficient, however, Avrami model provided a slightly better fit rather than the Malkin model in the present study. Malkin $C_{1}$ also exhibits similar temperature dependence to that of the crystallization rate constants in the use of Avrami and Tobin models. 
Table IV. Malkin kinetics parameters

\begin{tabular}{lcccc}
\hline \multirow{2}{*}{ Sample } & $\begin{array}{c}T_{\mathrm{c}} \\
\left({ }^{\circ} \mathrm{C}\right)\end{array}$ & $C_{0}$ & $\begin{array}{c}C_{1} \\
\left(\mathrm{~min}^{-1}\right)\end{array}$ & $R^{2}$ \\
\hline PEGMA & 84 & 4.32 & 0.428 & 0.9988 \\
\cline { 2 - 5 } & 85 & 4.46 & 0.318 & 0.9987 \\
\cline { 2 - 5 } & 86 & 4.23 & 0.198 & 0.9984 \\
\cline { 2 - 5 } PEGMA/Silica & 87 & 4.65 & 0.155 & 0.9984 \\
\cline { 2 - 5 } & 85 & 3.75 & 0.751 & 0.9972 \\
\cline { 2 - 5 } & 86 & 3.57 & 0.569 & 0.9975 \\
\cline { 2 - 5 } & 87 & 3.22 & 0.495 & 0.9968 \\
\cline { 2 - 5 } PEGMA/A-Silica & 88 & 4.47 & 0.422 & 0.9971 \\
\cline { 2 - 5 } & 90 & 4.42 & 0.366 & 0.9981 \\
\cline { 2 - 5 } & 87 & 5.40 & 0.301 & 0.9983 \\
\cline { 2 - 5 } & 88 & 3.96 & 0.713 & 0.9976 \\
\cline { 2 - 5 } & 89 & 4.08 & 0.453 & 0.9979 \\
\hline & 90 & 7.12 & 0.413 & 0.9980 \\
\cline { 2 - 5 } & 91 & 8.02 & 0.299 & 0.9979 \\
\cline { 2 - 5 } & 92 & 7.47 & 0.231 & 0.9985 \\
\hline
\end{tabular}

\section{Urbanovici-Segal Analysis}

Urbanovici and Segal ${ }^{49}$ suggested a kinetic equation:

$$
X_{t}=1-\left[1+(r-1)\left(K_{\mathrm{us}} t\right)^{n_{\mathrm{us}}}\right]^{1 /(1-r)}
$$

where $K_{\mathrm{us}}$ and $n_{\mathrm{us}}$ are the Urbanovici and Segal crystallization rate constant and exponent, respectively. When $r$ approaches unity, the Urbanovici-Segal equation reduces to the Avrami model, suggesting $r$ is indicative of deviation of the former equation from the latter equation. $K_{\text {us }}$ and $n_{\text {us }}$ have a physical meaning similar to $K_{\mathrm{a}}$ and $n_{\mathrm{a}}$, respectively, in the Avrami equation.

Equation 9 was applied to fitting of the present experimental data and the result are shown in Table V. When $r=1.03$ (in PEGMA/A-Silica at $91^{\circ} \mathrm{C}$ ), $n_{\mathrm{a}}$ and $n_{\mathrm{us}}, K_{\mathrm{a}}$ and $K_{\mathrm{us}}$ were almost the same. When $r>1$, the values of Urbanovici-Segal kinetics parameters were greater than those of Avrami parameters. With $r=1.25$ (in PEGMA/Silica at $87^{\circ} \mathrm{C}$ ), the difference between $n_{\mathrm{us}}$ and $n_{\mathrm{a}}$ was as much as $15.0 \%$ and that between $K_{\text {us }}$ and $K_{\mathrm{a}}$ was as much as $10.3 \%$. When $r<1$, the values of Urbanovici-Segal kinetics parameters were less than those of Avrami parameters. With $r=0.73$ (in neat PEGMA at $86^{\circ} \mathrm{C}$ ), the difference between $n_{\text {us }}$ and $n_{\mathrm{a}}$ was as much as $-13.5 \%$ and that between $K_{\text {us }}$ and $K_{\mathrm{a}}$ was as much as $-11.3 \%$. However, the results of the Urbanovici-Segal analysis were similar in the $T_{\mathrm{c}}$ dependence of the crystallization kinetics to those revealed by the Avami, Tobin and Malkin models, for any of the three series of samples.
Table V. Urbanovici-Segal Parameters

\begin{tabular}{lccccc}
\hline \multirow{2}{*}{ Sample } & $\begin{array}{c}T_{\mathrm{c}} \\
\left({ }^{\circ} \mathrm{C}\right)\end{array}$ & $n_{\mathrm{us}}$ & $r$ & $\begin{array}{c}K_{\mathrm{us}} \\
\left(\mathrm{min}^{-1}\right)\end{array}$ & $R^{2}$ \\
\hline PEGMA & 84 & 1.47 & 0.89 & 0.178 & 0.9998 \\
\cline { 2 - 6 } & 85 & 1.43 & 0.83 & 0.127 & 0.9997 \\
\cline { 2 - 6 } & 86 & 1.34 & 0.73 & 0.077 & 0.9997 \\
\cline { 2 - 6 } & 87 & 1.38 & 0.75 & 0.059 & 0.9997 \\
\hline PEGMA/Silica & 85 & 1.71 & 1.23 & 0.375 & 0.9995 \\
\cline { 2 - 6 } & 86 & 1.63 & 1.17 & 0.281 & 0.9994 \\
\cline { 2 - 6 } & 87 & 1.68 & 1.25 & 0.261 & 0.9993 \\
\cline { 2 - 6 } & 88 & 1.71 & 1.17 & 0.193 & 0.9992 \\
\hline PEGMA/A-Silica & 89 & 1.88 & 1.03 & 0.126 & 0.9995 \\
\cline { 2 - 6 } & 90 & 1.83 & 0.87 & 0.092 & 0.9996 \\
\cline { 2 - 6 } & 87 & 1.83 & 1.22 & 0.503 & 0.9996 \\
\hline & 88 & 1.70 & 1.20 & 0.344 & 0.9996 \\
\cline { 2 - 6 } & 89 & 1.72 & 1.21 & 0.217 & 0.9994 \\
\cline { 2 - 6 } & 90 & 1.78 & 1.05 & 0.156 & 0.9995 \\
\cline { 2 - 6 } & 91 & 1.79 & 1.03 & 0.108 & 0.9994 \\
\cline { 2 - 6 } & 92 & 1.73 & 0.97 & 0.083 & 0.9997 \\
\hline
\end{tabular}

\section{Comparison of Kinetic Models}

Variation of relative crystallinity as a function of time, constructed in regression with the four kinetic models is shown in Figure 6 for the three series of samples crystallized isothermally. The Avrami and Malkin models provided a good fit to the experimental data when $X_{t}<0.85$, but both models underestimated the data when $X_{t}>0.85$. This derivation may be ascribed to an effect of the secondary crystallization occurring at later stage. The Tobin model was less satisfactory in describing the experimental data for all samples, though the growth impingement taken into consideration. The Urbanovici-Segal model provided the best fit over the entire range of the crystallinity data for all the samples with the highest regression coefficient $\left(R^{2}\right)$ (see Tables II-V).

To obtain crystallization rate for comparison, undercooling $\left(T_{\mathrm{m}}^{\mathrm{ONLHW}}-T_{\mathrm{c}}\right)$ and crystallization rate constants calculated from the four kinetic models are shown in Figures 7a, 7b, 7c and 7d. All models showed similar that the crystallization rate constants increased with undercooling, indicating higher crystallization rate at greater undercooling. To reach a specific value of rate constant, PEGMA/A-Silica needed to be imposed by the highest undercooling followed by PEGMA/Silica and PEGMA, regarding the degree of undercooling required. This indicates that the crystallization rate follows the order of PEGMA > PEGMA/Silica > PEGMA/A-Silica. ${ }^{50}$ The overall crystallization rate is governed by nucleation and diffusion ${ }^{51}$ and the above ranking can be explained by silica particles hindering the crystallization by slowing down the diffusion of PEGMA chains. ${ }^{52-54}$ 


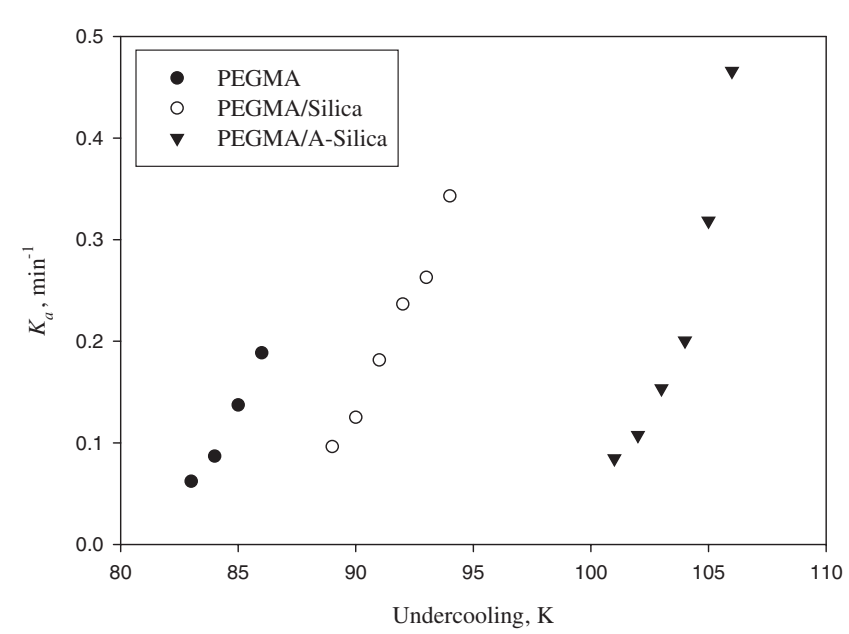

(a)

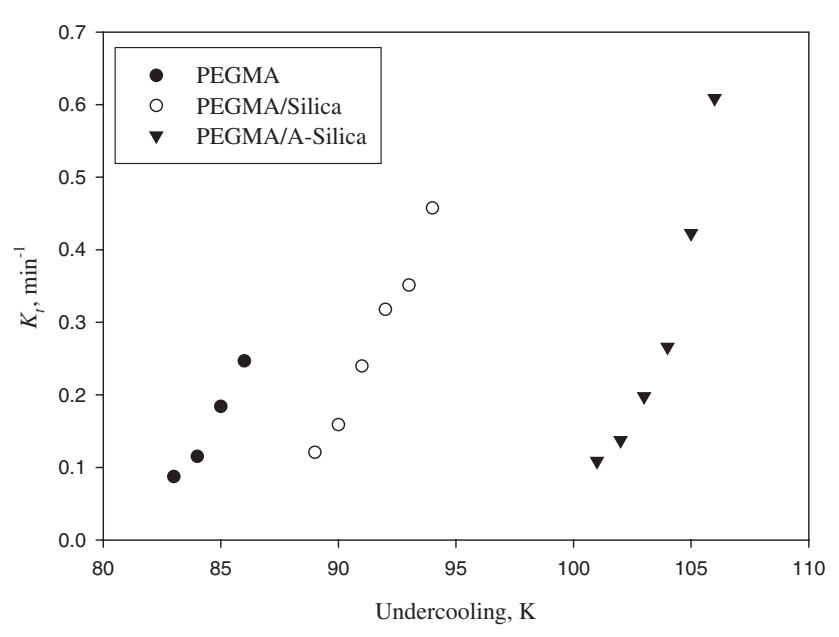

(b)

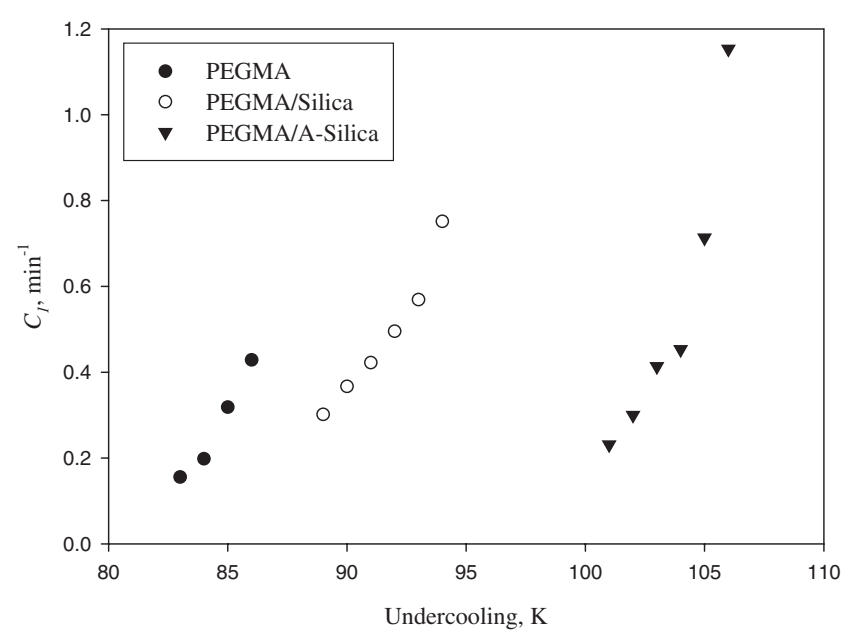

(c)

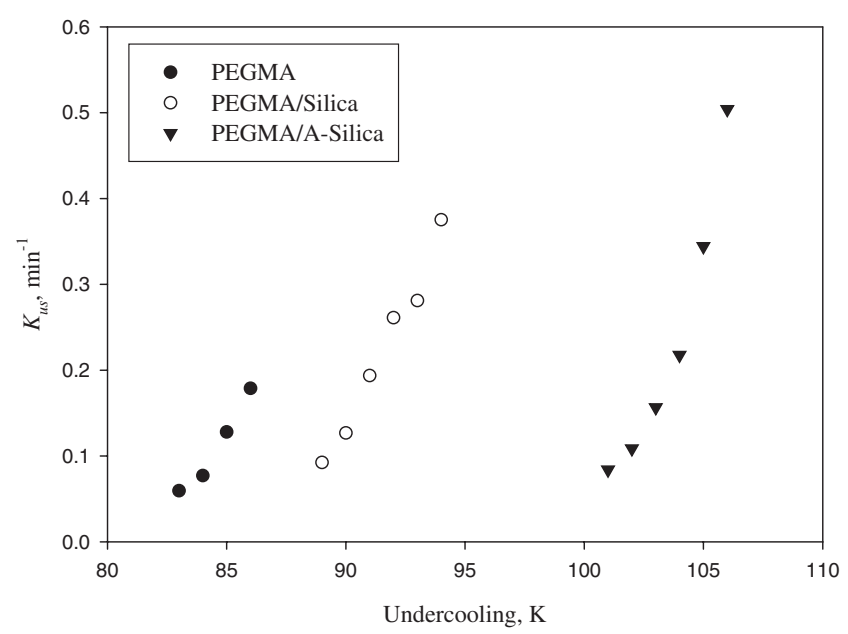

(d)

Figure 7. Relation of undercooling and rate constants, evaluated from the kinetic models of: (a) Avrami, (b) Tobin, (c) Malkin, and (d) Urbanovici and Segal.

This is similar to the spherulite growth rate of poly(ethylene oxide) retarded by the presence of the nano-silica ${ }^{55} \mathrm{~A}$-Silica further reduced the crystallization rate because the strong interaction is present between A-Silica and PEGMA as mentioned above.

\section{CONCLUSIONS}

Surface modification by $\gamma$-aminopropyltriethoxysilane greatly improved the dispersion of nano-silica (A-Silica) particles in PEGMA matrix because of better compatibility between A-Silica particles and PEGMA matrix. The addition of $3 \mathrm{wt} \%$ A-Silica increased the equilibrium melting temperature of PEGMA/A-Silica estimated from linear or nonlinear $\mathrm{H}-\mathrm{W}$. Four kinetic models, of Avrami, Tobin, Malkin, and Urbanovici-Segal, predicted the same ranking order in crystallization rate: PEGMA > PEGMA/
Silica > PEGMA/A-Silica. Urbanovici-Segal provided the best fit to the experimental data.

\section{REFERENCES}

1. J. Ma, Z. Qi, and Y. Hu, J. Appl. Polym. Sci., 82, 3611 (2001).

2. M. Kawasumi, N. Hasegawa, M. Kato, A. Usuki, and A. Okada, Macromolecules, 30, 6333 (1997).

3. W. B. Xu, M. L. Ge, and P. S. He, J. Appl. Polym. Sci., 82, 2281 (2001).

4. W. B. Xu, M. L. Ge, and P. S. He, J. Polym. Sci., Part B: Polym. Phys., 40, 408 (2002).

5. F. Stricher, M. Bruch, and R. Mulhaupt, Polymer, 38, 5347 (1997).

6. N. Qureshi, E. V. Stepanov, D. Schiraldi, A. Hiltner A, and E. Baer, J. Polym. Sci., Part B: Polym. Phys., 38, 1679 (2000).

7. T. M. Wu, C. C. Chang, and T. L. Yu, J. Polym. Sci., Part B: 
Polym. Phys., 38, 2515 (2000).

8. T. M. Wu, S. F. Hsu, C. F. Chien, and J. Y. Wu Baer, Polym. Eng. Sci., 44, 2288 (2004).

9. B. Novak, Adv. Mater., 5, 422 (1993).

10. M. Kawasumi, N. Hasegawa, M. Kato, A. Usuki, and A. Okada, Macromolecules, 30, 6333 (1997).

11. D. Kaempfer, R. Thomann, and R. Mohlhaupt, Polymer, 43, 2909 (2002).

12. S. Sepeur, N. Kunze, B. Werner, and H. Schmidt, Thin Solid Films, 351, 216 (1999).

13. F. Bauer, H. Ernst, U. Decker, M. Findeisen, H. J. Glasel, E. Hartmann, H. Langguth, R. Mehnert, and C. Peuker, Macromol. Chem. Phys., 201, 2654 (2000).

14. M. Templin, U. Wiesner, and H. W. Spiess, Adv. Mater., 9, 814 (1997).

15. Y. Sorek, M. Zezin, R. Reisfeld, T. Hurvits, and S. Ruschin, Chem. Mater., 9, 670 (1997).

16. J. A. Lin, J. Siddiqui, and R. M. Ottenbrite, Polym. Adv. Technol., 122, 285 (2001).

17. H. Pfeifer and H. Winkler, "Magnetic Resonance Methods in: Preparative Chemistry Using Supported Reagents," Academic Press, New York, N.Y., 1987, p 151.

18. F. Bauer, V. Sauerland, H. J. Glsel, H. Ernst, M. Findeisen, E. Hartmann, H. Langguth, B. Marquardt, and R. Mehnert, Macromol. Mater. Eng., 287, 546 (2002).

19. H. J. Glase, F. Bauer, H. Ernst, M. Findeisen, E. Hartmann, H. Langguth, R. Mehnert, and R. Schubert, Macromol. Chem. Phys., 201, 2765 (2000).

20. I. Dobas and J. Eichler, Coll. Czech. Chem. Commun., 38, 2602 (1973).

21. J. Shcchter and J. Wynstra, Ind. Eng. Chem., 48, 94 (1956).

22. J. V. Duffy, E. Hui, and B. Hartmann, J. Appl. Polym. Sci., 33, 2959 (1987).

23. D. Glover, J. V. Duffy, and B. Harmann, J. Polm. Sci., Part A: Polym. Chem., 26, 79 (1988).

24. J. Kalal, F. Ssvec, and V. Marousek, J. Polym. Sci., 47, 155 (1974).

25. J. D. Hoffman, G. T. Davis, and J. I. Lauritzen, "Treaties on Solid State Chemistry," Vol. 3, N. B. Hannay, Ed., Plenum Press, New York, N.Y., 1976, Chapt. 7.

26. J. D. Hoffman and R. L. Miller, Polymer, 38, 3151 (1997).

27. K, Armitstead and G. Goldbeck-Wood, Adv. Polym. Sci., 100, 219 (1992).

28. H. G. Kim and R. E. Robertson, J. Polym. Sci., Part B: Polym. Phys., 36, 133 (1998).
29. P. J. Flory and A. Vrij, J. Am. Chem. Soc., 85, 3548 (1963).

30. J. D. Hoffman and J. J. Weeks, J. Res. Nat. Bur. Stand., 66A, 13 (1962).

31. S. W. Lee, B. Lee, and M. Ree, Macromol. Chem. Phys., 201, 453 (2000).

32. R. G. Alamo, B. D. Viers, and L. Mandelkern, Macromolecules, 28, 3205 (1995).

33. C. P. Buckley and A. J. Kovacs, Colloid Polym. Sci., 254, 695 (1976).

34. H. Marand, J. Xu, and S. Srinivas, Macromolecules, 31, 8219 (1998).

35. C. C. Lin, Polym. Eng. Sci., 23, 113 (1983).

36. M. J. Avrami, Chem. Phys., 7, 1103 (1939).

37. M. J. Avrami, Chem. Phys., 8, 212 (1940).

38. M. J. Avrami, Chem. Phys., 9, 177 (1941).

39. P. Supaphol and J. E. Spruiell, Polymer, 42, 699 (2001).

40. B. Wunderlich, "Macromolecular Physics," Vol. 2, Academic Press, New York, N.Y., 1976.

41. P. Supaphol, Thermochimi. Acta, 170, 37 (2001).

42. M. C. Tobin, J. Polym. Sci., Polym. Phys. Ed., 12, 399 (1974).

43. M. C. Tobin, J. Polym. Sci., Polym. Phys. Ed., 14, 2253 (1976).

44. M. C. Tobin, J. Polym. Sci., Polym. Phys. Ed., 15, 2269 (1977).

45. K. Ravindranath and J. P. Jog, J. Appl. Polym. Sci., 49, 1395 (1993).

46. J. J. C. Cruz-Pinto, J. A. Martins, and M. J. Oliveira, Colloid Polym. Sci., 272, 1 (1994).

47. P. Supaphol and J. E. Spruiell, J. Macromol. Sci., Phys., B39, 257 (2000).

48. A. Y. Malkin, V. P. Beghishev, I. A. Keapin, and S. A. Bolgov, Polym. Eng. Sci., 24, 1396 (1984).

49. E. Urbanovici and E. Segal, Thermochim Acta, 171, 87 (1990).

50. V. Causin, C. Marega, A. Marigo, L. Valentini, and J. M. Kenny, Macromolecules, 38, 409 (2005).

51. J. G. Fatou, Makromol. Chem., 7, 131 (1984).

52. G. Zhang and D. Yan, J. Appl. Polym. Sci., 88, 2181(2003).

53. C. C. Ma, C. T. Kuo, H. C. Kuan, and C. L. Chiang, J. Appl. Polym. Sci., 88, 1686 (2003).

54. C. G. Jimenez, N. Ogata, H. Kawai, and T. Ogihara, J. Appl. Polym. Sci., 64, 2211 (1997).

55. A. J. Waddon and Z. S. Petrovic, Polym. J., 34, 876 (2002). 